\title{
CHYTRIDIOMYCOTA E OOMYCOTA DA REPRESA DO GUARAPIRANGA, SÃO PAULO, SP1
}

\author{
Maristela da Rocha ${ }^{2}$ \\ Carmen Lidia Amorim Pires Zottarelli
}

Recebido em 15/04/2001. Aceito em 15/01/2002

\begin{abstract}
RESUMO - (Chytridiomycota e Oomycota da Represa do Guarapiranga, São Paulo, SP). Quinze táxons de Chytridiomycota e 18 de Oomycota foram isolados de amostras de água e solo na Represa do Guarapiranga, por meio de técnica de iscagem, com substratos celulósicos, queratinosos e quitinosos. Dos táxons de Chytridiomycota isolados, um pertence aos Blastocladiales, onze aos Chytridiales e três aos Spizellomycetales. Dos táxons de Oomycota, treze pertencem aos Saprolegniales e cinco aos Peronosporales. Septochytrium marilandicum Karling é citada pela primeira vez para o Brasil.
\end{abstract}

Palavras-chave - Blastocladiales, Chytridiales, Spizellomycetales, Saprolegniales, Peronosporales, fungos zoospóricos, biodiversidade

\begin{abstract}
Chytridiomycota and Oomycota from the Guarapiranga reservoir, São Paulo State, Brazil). Fifteen taxa of Chytridiomycota and eighteen of Oomycota were isolated from water and soil samples from the Guarapiranga reservoir, using a baiting technique with celulosic, chitinous and keratinous substrates. Among the taxa of Chytridiomycota isolated, one belongs to Blastocladiales, eleven to Chytridiales and three to Spizellomycetales. Among the Oomycota, thirteen are Saprolegniales and five Peronosporales. Septochytrium marilandicum Karling is mentioned for the first time in Brazil.
\end{abstract}

Key words - Blastocladiales, Chytridiales, Spizellomycetales, Saprolegniales, Peronosporales, zoosporic fungi, biodiversity

\footnotetext{
${ }^{1}$ Parte do trabalho de conclusão de curso de Bacharelado em Ciências Biológicas na Universidade de Santo Amaro (UNISA), São Paulo, SP.

${ }^{2}$ Instituto de Botânica, Seção de Micologia e Liquenologia, Caixa Postal 4005, CEP 01061-970, São Paulo, SP, Brasil.
} 


\section{Introdução}

Segundo Alexopoulos et al. (1996), os filos Chytridiomycota e Oomycota, são pertencentes a diferentes reinos: Fungi e Stramenopila, sendo caracterizados como fungos zoospóricos por apresentarem flagelos em suas estruturas de reprodução assexuada e/ou sexuada. O tipo, número e inserção dos flagelos nos esporos são características que delimitam esses fungos nos respectivos filos, sendo que os representantes de Chytridiomycota apresentam um único flagelo tipo chicote posteriormente inserido no esporo, existindo também representantes poliflagelados, enquanto Oomycota, tem representantes biflagelados, de tipos diferentes, penado e chicote, inseridos apical ou lateralmente.

Esses fungos possuem distribuição cosmopolita e ocorrem geralmente como sapróbios em diferentes tipos de substratos; alguns podem ser parasitas de algas, peixes, plantas fanerogâmicas, crustáceos e outros fungos, contribuindo desta forma para a manutenção do fluxo de energia e produtividade nos ecossistemas terrestres e aquáticos (Dick 1976).

A represa do Guarapiranga é hoje um dos principais mananciais de abastecimento da cidade de São Paulo, sendo responsável pelo suprimento de água de $20 \%$ da população da região metropolitana (CETESB 1998), mas apesar disto apresenta alto grau de eutrofização devido ao constante despejo de esgoto doméstico e industrial. De acordo com a Secretaria de Estado do Meio Ambiente, a situação dessa represa é bastante crítica, pois sua capacidade assimilativa é superior a entrada de poluentes oriundos dos lançamentos de esgoto doméstico sem tratamento, agravada ainda pelo desmatamento, instalação de favelas nas margens e pelo carreamento de águas pluviais e lixo nos seus cursos d'água (CETESB 1994).

Diante da importância da represa, diversos estudos têm sido conduzidos visando o conhecimento, recuperação e preservação do manancial.
Com fungos, ainda são poucos os estudos. Apolinário \& Milanez (1986a, b) realizaram levantamento de leveduras e leveduróides existentes na água da represa; Malosso (1999) estudou os hifomicetos aquáticos em folhas submersas; Domingues (1998) realizou levantamento da micota terrestre. Outros estudos foram concentrados na Ilha dos Eucaliptos, localizada na parte central da represa: Santos et al. (1996) realizaram um estudo sobre Oomycetes; Wellbaum et al. (1999) realizaram levantamento dos fungos filamentosos em folhas do ambiente terrestre e aquático; Gomes (1997) investigou os fungos micorrízicos arbusculares e Santos et al. (1998) identificaram fungos filamentosos de solo.

O objetivo do trabalho foi contribuir para o conhecimento da diversidade da micota zoospórica de água e solo, sendo o primeiro levantamento sistemático deste grupo de fungos em manancial de abastecimento na cidade de São Paulo.

\section{Material e métodos}

Para o levantamento da diversidade dos fungos zoospóricos da represa foi utilizada a técnica descrita por Milanez (1989), que consiste na iscagem de amostras de água e solo com substratos celulósicos, queratinosos e quitinosos. As coletas foram realizadas bimestralmente, em seis pontos de coleta, no período de agosto/1997 a junho/1998. Para a identificação dos táxons foram utilizados os trabalhos de Johnson (1956), Sparrow (1960), Scott (1961), Seymour (1970), Karling (1977), Dick (1973) e Plaats-Niterink (1981), além de outros contendo as descrições originais.

\section{Resultados e discussão}

Foram isolados 33 táxons, sendo 15 pertencentes ao filo Chytridiomycota e 18 ao Oomycota. Dos Chytridiomycota, um táxon é pertencente à Blastocladiales, onze à 
Chytridiales e três à Spizellomycetales. Dos Oomycota, treze são pertencentes à Saprolegniales e cinco à Peronosporales.

\section{CHYTRIDIOMYCOTA}

\section{BLASTOCLADIALES}

Catenariaceae

Catenophlyctis variabilis Karling, Amer. J. Bot. 52(2):133-138. 1965.

Fig. 1

Talo eucárpico, policêntrico, intramatrical.

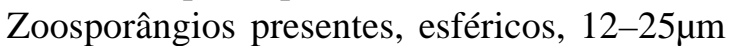
diâm., e irregulares; parede lisa. Tubo de descarga para liberação dos zoosporos. Sistema rizoidal bastante desenvolvido a partir de vários pontos da parede do zoosporângio. Esporos de resistência não observados.

Distribuição geográfica no Brasil: ocorre nos estados do AM, RO (Karling 1947) e SP (Milanez 1984a; Pires-Zottarelli 1990; Schoenlein-Crusius et al. 1992; SchoenleinCrusius \& Milanez 1998; Pires-Zottarelli 1999). Comentários: as características apresentadas pelos espécimes concordam com as descritas por Karling (1965) e Pires-Zottarelli (1990, 1999), tendo sido isolados de ecdise de cobra, em amostras de água e solo.

\section{CHYTRIDIALES \\ Chytridiaceae}

Cylindrochytridium johnstonii Karling, Bull. Torrey Bot. Club. 68:383. 1941.

Fig. 2

Talo eucárpico, monocêntrico, extraintramatrical. Zoosporângios operculados, cilíndricos, (62-)75-100 x 20-30um, ocasionalmente ovais ou irregulares; parede lisa. Zoosporos encistados 7,5 $\mu \mathrm{m}$ diâm., com uma gotícula lipídica conspícua. Sistema rizoidal originado da porção basal do zoosporângio, apresentando células catenuladas esféricas ou cilíndricas. Liberação dos zoosporos por meio de um opérculo apical. Esporos de resistência não observados.

Distribuição geográfica no Brasil: ocorrência registrada somente no Estado de São Paulo - SP (Pires-Zottarelli \& Milanez 1993).

Comentários: as características dos espécimes diferem do mencionado na descrição original de Karling (1941), o qual cita zoosporângios

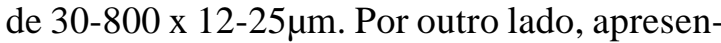
tam zoosporângios maiores que os relatados por Pires-Zottarelli \& Milanez (1993), que menci-

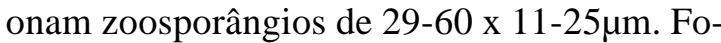
ram isolados de palha de milho, em amostras de água.

Chytriomyces hialinus Karling, Amer. J. Bot. 32:363. 1945.

Fig. 3-4

Talo eucárpico, monocêntrico, extra e/ou intramatrical. Zoosporângios operculados, hialinos, esféricos, $25-47 \mu \mathrm{m}$ diâm; parede lisa. Apófise sub-esporangial presente ou ausente. Liberação dos zoosporos por meio de opérculo localizado apical ou subapicalmente nos zoosporângios. Zoosporos encistados, $5 \mu \mathrm{m}$ diâm., com uma gotícula lipídica. Esporo de resistência esférico, 15-20 $\mu$ m; parede lisa.

Distribuição geográfica no Brasil: ocorre no AM (Karling, 1945a) e SP (Booth 1979).

Comentários: os espécimes possuem características que estão de acordo com a descrição original de Karling (1945a). Foram isolados de exo-esqueleto de camarão, em amostras de água.

Rhizophydium elyensis Sparrow, Trans. Brit. mycol. Soc. 40:523-535. 1957.

Fig. 5

Talo eucárpico, monocêntrico, extraintramatrical. Zoosporângios hialinos, esféricos,

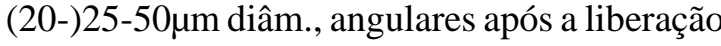
dos zoosporos pela presença de poros; parede lisa, com 1-5 poros. Rizóides delicados, ramificações saindo da base do zooporângio ou de um 


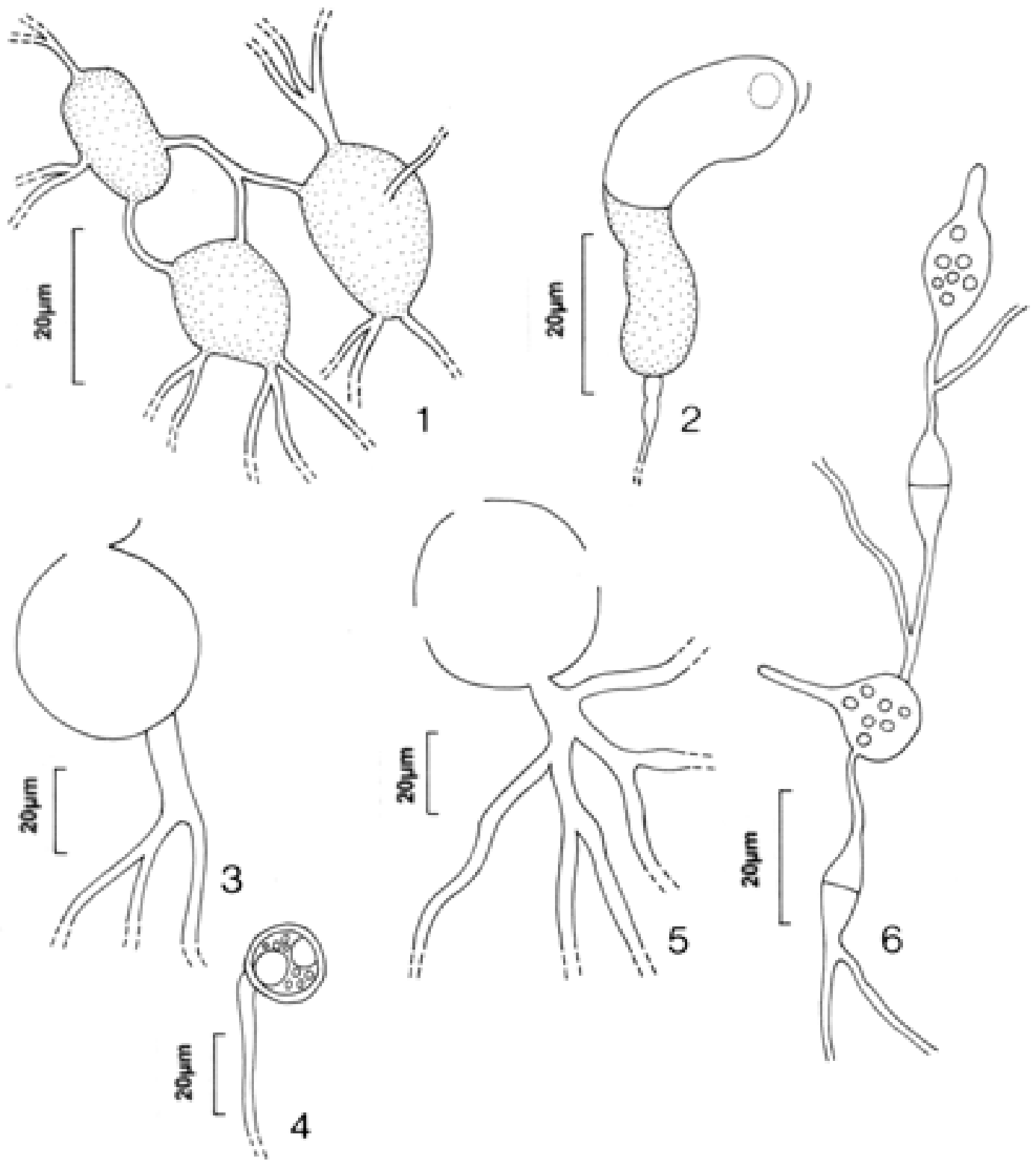

Figuras 1-6. 1) Catenophlyctis variabilis: talo policêntrico; 2) Cylindrochytridium johnstonii: zoosporângio operculado; 3-4) Chytriomyces hialinus: 3) zoosporângio operculado, 4) esporo de resistência; 5) Rhizophydium elyensis: zoosporângio com poros; 6) Cladochytrium replicatum: zoosporângios e células turbinadas. 
eixo principal. Zoosporos encistados 7,5 $\mu \mathrm{m}$ diâm., com uma gotícula lipídica excêntrica. Esporos de resistência não observados.

Distribuição geográfica no Brasil: ocorrência registrada em SP (Schoenlein-Crusius et al. 1992; Pires-Zottarelli \& Milanez 1993; Schoenlein-Crusius \& Milanez 1998; PiresZottarelli et al. 1996a; Pires-Zottarelli 1999).

Comentários: os espécimes apresentaram zoosporângios e zoosporos maiores que os citados por Sparrow (1957), que cita zoosporângios de $23-25 \mu \mathrm{m}$ e zoosporos de $2-5 \mu \mathrm{m}$, por PiresZottarelli et al. (1996a) que mencionam zoosporângios de 13-35um; no entanto, as dimensões concordam com a descrição de PiresZottarelli (1999).Os zoosporos foram maiores que os citados por Pires-Zottarelli \& Milanez (1993) e Pires-Zottarelli et al. (1996a), os quais citam zoosporos de $2-4 \mu \mathrm{m}$. Foram isolados de ecdise de cobra, em amostras de água e solo.

Cladochytriaceae

Cladochytrium replicatum Karling, Amer. J. Bot. 18:538. 1931.

Fig. 6

Talo eucárpico, policêntrico, intramatrical. Zoosporângios inoperculados, terminais, piriformes e/ou ovais, 15-22(-27) x (10-)12-17 $\mu \mathrm{m}$, raramente esféricos, com um único tubo de descarga cilíndrico para liberação dos zoosporos; parede lisa. Sistema rizoidal delicado, extenso, apresentando células turbinadas septadas em intervalos freqüentes. Zoosporos encistados $7,5 \mu \mathrm{m}$ diâm., com um distinto glóbulo alaranjado. Esporos de resistência não observados.

Distribuição geográfica Brasil: ocorre no AC, AM, CE e MT (Karling 1945b); SP (Rogers et al. 1970; Pires-Zottarelli 1990; Schoenlein-Crusius et al. 1990; Pires-Zottarelli et al. 1996a; SchoenleinCrusius \& Milanez 1998; Pires-Zottarelli 1999).

Comentários: as características dos espécimes estão de acordo com a descrição de Sparrow (1960), Pires-Zottarelli et al. (1996a) e Pires-
Zottarelli (1999). Foram isolados de celofane, palha de milho e epiderme de cebola, em amostras de água.

Nowakowskiella elegans (Nowak.) Schroeter, Engler and Prantl, Naturlichen Pflanzenfam. 1(1):82. 1892 (1893).

Fig. 7

Talo eucárpico, policêntrico, extra-intramatrical. Rizomicélio extenso, ramificado. Zoosporângios operculados, hialinos, apofisados ou não, esféricos, 25-40 um diâm. ou piriformes, 27-40 x 25$30 \mu \mathrm{m}$; parede lisa; tubo de descarga presente; proliferação interna presente. Zoosporos encistados normalmente $10 \mu \mathrm{m}$ diâm. Esporos de resistência não observados.

Distribuição geográfica no Brasil: ocorre na PB (Joffily 1947) e SP (Lyra \& Milanez 1974; Milanez 1984a; Pires-Zottarelli 1990; Schoenlein-Crusius et al. 1990; SchoenleinCrusius et al. 1992; Schoenlein-Crusius \& Milanez 1998; Pires-Zottarelli et al. 1996a e Pires-Zottarelli 1999).

Comentários: os espécimes apresentaram zoosporângios e zoosporos maiores que os citados por Pires-Zottarelli (1990), que cita

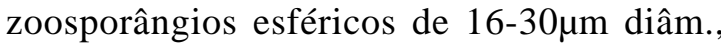
piriformes de 17-28 x 14-32 $\mu \mathrm{m}$, e zoosporos de 4-8 $\mu$ m.; também difere dos valores encontrados por Pires-Zottarelli et al. (1996a) que mencionam zoosporângios esféricos de $10-25 \mu \mathrm{m}$, piriformes de 9-14 x 18-20 $\mu \mathrm{m}$ e zoosporos de 3-6um e Pires-Zottarelli (1999), que cita

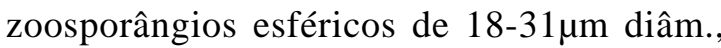
piriformes, $19-31 \times 16-33 \mu \mathrm{m}$ e zoosporos encistados 5,5-7 $\mu \mathrm{m}$ diâm. Diferem da descrição de Sparrow (1960) no tamanho dos zoosporos, o autor cita de 5,0-7,5 $\mu \mathrm{m}$ diâm. Foram isolados de celofane, palha de milho e epiderme de cebola, em amostras de água e solo.

Nowakowskiella multispora Karling, Sydowia 17 (1-6):314-319. 1964.

Fig. 8 
Talo eucárpico, policêntrico, extra-intramatrical. Rizomicélio extenso, ramificado. Zoosporângios operculados, hialinos, não apofisados, piriformes 25-30 x 15-22 $\mu \mathrm{m}$, ocasionalmente esféricos e ovais; parede lisa. Tubo de descarga presente. Esporos de resistência intercalares no rizomicélio, ovais, $15-20 \times 12-17 \mu \mathrm{m}$ e esféricos, 12-17 $\mu \mathrm{m}$ diâm.; parede espessada, lisa.

Distribuição geográfica no Brasil: ocorre em SP (Pires-Zottarelli 1999).

Comentários: as características dos espécimes concordam com a descrição original de Karling (1964) e com a de Pires-Zottarelli (1999). Foram isolados de palha de milho, celofane e epiderme de cebola, em amostras de água e solo.

Septochytrium marilandicum Karling, Bull. Torrey Bot. Club. 78:38-43. 1951.

Fig. 9-10

Talo eucárpico, policêntrico, extra-intramatrical. Rizomicélio ramificado, não septado, trabéculas não verificadas. Zoosporângios operculados, esféricos (22-)25-50(-57)um diâm., ocasionalmente ovais; parede lisa, espessa. Zoosporos normalmente $5 \mu \mathrm{m}$ diâm., com várias gotículas lipídicas. Esporos de resistência esféricos, 12$20 \mu \mathrm{m}$; parede lisa e ornamentada; espessa; coloração âmbar.

Comentários: as características apresentadas pelos espécimes estão de acordo com a descrição original de Karling (1951). Os esporos de resistência concordam com o descrito por Willoughby (1964). Foram isolados em celofane, palha de milho e epiderme de cebola, em amostras de solo. Trata-se da primeira citação para o Brasil.

Septochytrium variabile Berdan, Amer. J. Bot. 26:461. 1939.

Fig. 11

Talo eucárpico, policêntrico, extra-intramatrical. Rizomicélio ramificado, septado. Zoosporângios operculados, esféricos 22-25(-30)um diâm. ou ovais (20-)25-50 x (12-)15-30 (-37) $\mu \mathrm{m}$; parede lisa, espessa. Zoosporos encistados (2,5-)5-7,5(10) $\mu \mathrm{m}$ diâm., com uma gotícula lipídica conspícua. Esporos de resistência não observados.

Distribuição geográfica no Brasil: ocorre em SP (Booth 1979; Pires-Zottarelli \& Milanez 1993; Pires-Zottarelli 1999).

Comentários: as caracterísitcas apresentadas pelos espécimes concordam com as descrições de Sparrow (1960) e Pires-Zottarelli \& Milanez (1993). Diferem da descrição de Pires-Zottarelli (1999), que cita zoosporângios esféricos maio-

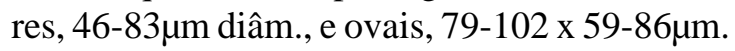
Foram isolados de celofane, palha de milho e epiderme de cebola, em amostras de água e solo.

Endochytriaceae

Catenochytridium kevorkianii Sparrow, Rev. Soc. Cubana Bot. 9:70. 1952.

Fig. 12

Talo eucárpico, monocêntrico, extra e/ou intramatrical. Zoosporângios operculados, irre-

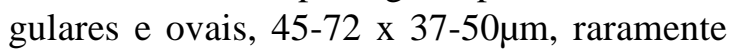
esféricos ou subesféricos, hialinos; parede lisa, ocasionalmente com algumas protuberâncias. Apófises presentes, simples ou compostas, esféricas ou subesféricas; rizóides catenulados. Cisto do zoosporângio evidente localizado basalmente. Zoosporos encistados 7,5 $\mu$ m diâm., com uma gotícula lipídica conspícua. Esporos de resistência não observados.

Distribuição geográfica no Brasil: ocorre em SP (Pires-Zottarelli \& Milanez 1993 e PiresZottarelli 1999).

Comentários: os espécimes possuem zoosporângios maiores que os citados por Sparrow (1952), que menciona zoosporângios de 40-43 x 35-36 $\mu$ m., mas concorda com PiresZottarelli \& Milanez (1993). Difere da descrição de Pires-Zottarelli (1999), que cita

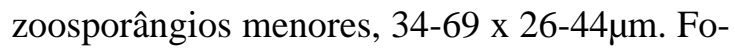
ram isolados de palha de milho e epiderme de cebola, em amostras de solo. 


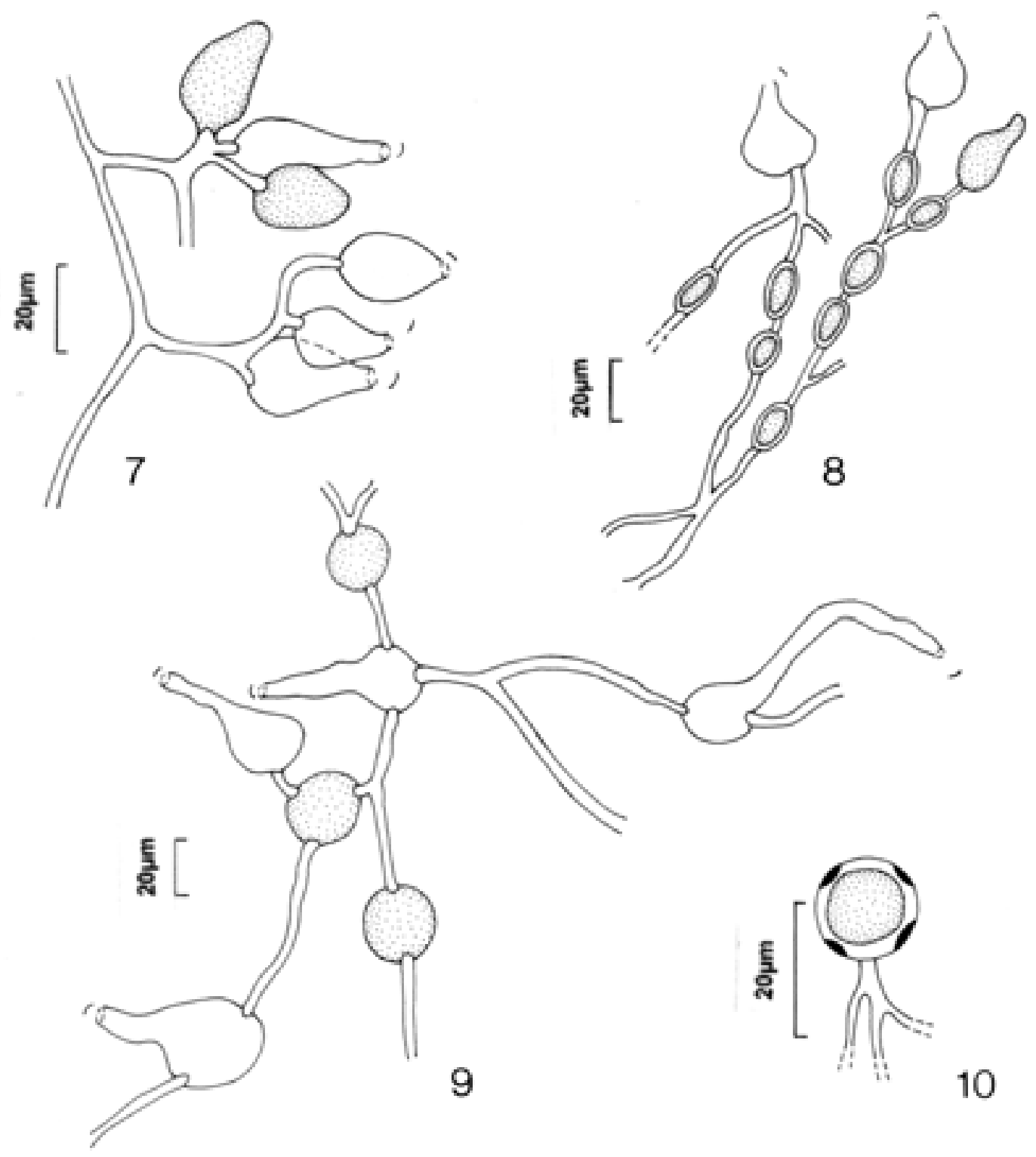

Figuras 7-10. 7) Nowakowskiella elegans: zoosporângios operculados; 8) Nowakowskiella multispora: talo policêntrico, esporos de resistência dentro do rizomicélio e zoosporângios operculados; 9-10) Septochytrium marilandicum: 9) zoosporângios operculados, 10) esporo de resistência. 
Diplophlyctis complicata (Willoughby) Dogma, Nova Hedwigia. 25: 144-151. 1974.

Fig. 13-14

Talo eucárpico, monocêntrico, extraintramatrical. Zoosporângios inoperculados, esféricos, 37-62 $\mu \mathrm{m}$ diâm., ocasionalmente piriformes, apofisados; parede lisa. Tubo de descarga dos zoosporos presente. Zoosporos encistados 7,5um diâm., com uma gotícula lipídica. Esporos de resistência ornamentados, esféricos, 17,5-25 um diâm., ornamentações "franjadas"; coloração âmbar.

Distribuição geográfica no Brasil: ocorre em SP (Pires-Zottarelli 1999).

Comentários: as características dos espécimes estão de acordo com descrição de Dogma (1974a). O material concorda com o descrito por Pires-Zottarelli (1999) no tamanho dos zoosporângios, e difere no tamanho dos esporos de resistência, citados como maiores, $23-42 \mu \mathrm{m}$ diâm. Foram isolados de palha de milho e epiderme de cebola, em amostras de água.

Diplophlyctis sarcoptoides (H.E. Petersen) Dogma, Nova Hedwigia. 25: 122-131. 1974.

Fig. 15-16

Talo eucárpico, monocêntrico, extraintramatrical. Zoosporângios ornamentados, esféricos; 20-33 $\mu$ m diâm. ou irregulares; ornamentações espinhosas e tuberculadas; apófise subesporangial bem desenvolvida, esférica, com vários eixos rizoidais. Zoosporos liberados através de poro ou por formação de papila. Esporos de resistência ornamentados como os

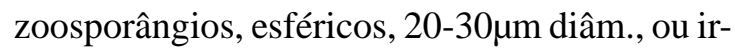
regulares, com apófise subesporangial.

Distribuição geográfica no Brasil: ocorre em RO (Karling 1945a); SP (Milanez 1984a; Pires-Zottarelli 1990; Schoenlein-Crusius et al. 1990; Schoenlein-Crusius et al. 1992; PiresZottarelli et al. 1996a; Pires-Zottarelli 1999).

Comentários: as características apresentadas pelos espécimes não diferem das descritas por Dogma (1974b), Pires-Zottarelli et al. (1996a) e Pires-Zottarelli (1999). Foram isolados de exo-esqueleto de camarão, em amostras de água e solo.

\section{SPIZELLOMYCETALES}

Spizellomycetaceae

Karlingia granulata Karling, Mycologia 39:5670. 1947.

Fig. 17-18

Talo eucárpico, monocêntrico, extraintramatrical. Sistema rizoidal ramificado. Zoosporângios exoperculados hialinos, não apofisados, esféricos (25-)37-50 (-62) $\mu$ m diâm., oval ou piriformes, 30-57 x 20-52 $\mu \mathrm{m}$ diâm.; parede espessa e lisa, tornando-se enrugada após liberação dos zoosporos. Zoosporos esféricos, 5-7,5 $\mu \mathrm{m}$ diâm.; com várias gotículas lipídicas. Esporos de resistência esféricos, âmbar, 1030um diâm.

Distribuição geográfica no Brasil: ocorre no MT (Karling 1947).

Comentários: as características apresentadas pelos espécimes estão de acordo com a descrição original de Karling (1947). Foram isolados de celofane, palha de milho e epiderme de cebola, em amostras de solo. É a primeira citação para o estado de São Paulo.

Karlingia rosea (de Bary \& Woronin) Johanson, Am. J. Bot. 31:399. 1944.

Fig. 19

Talo eucárpico, monocêntrico, extraintramatrical. Rizóides partindo de vários pontos da superfície do zoosporângio. Zoosporângios endoperculados, esféricos, 53186um diâm.; parede espessa e lisa, conteúdo róseo-alaranjado. Zoosporos esféricos, 7,5 $\mu \mathrm{m}$ diâm. Esporos de resistência não observados.

Distribuição geográfica no Brasil: ocorre no AC (Karling 1944c); AM (Karling 1947); PB (Joffily 1947); RO (Karling 1947; Dogma 1974b); SP(Joffily 1947; Lyra \& Milanez 1974; Booth 1979; Milanez 1984b; Schoenlein- 


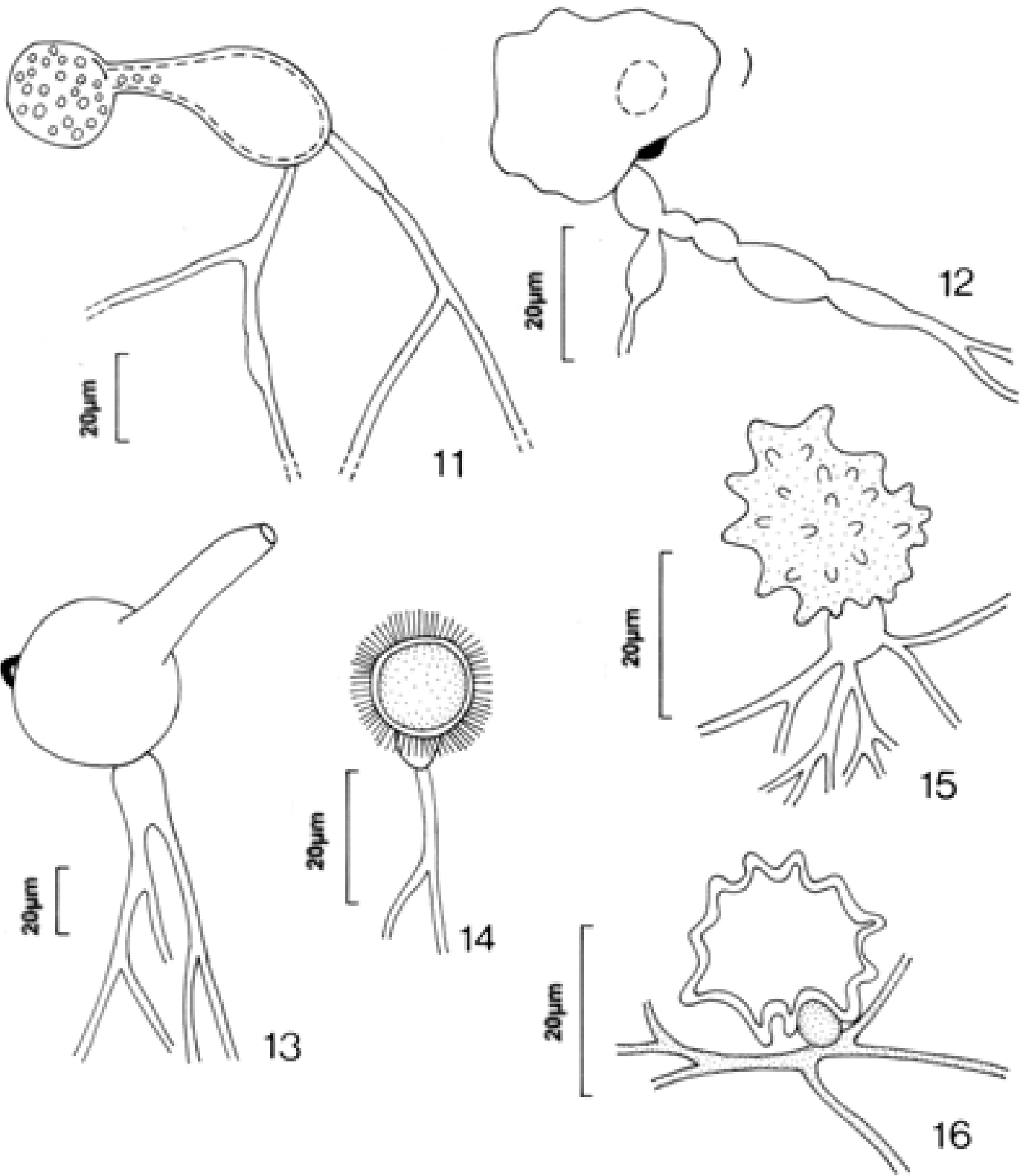

Figuras 11-16. 11) Septochytrium variabile: zoosporângio operculado; 12) Catenochytridium kevorkianii: zoosporângio operculado com cisto basal; 13-14) Diplophlyctis complicata: 13) zoosporângio inoperculado com cisto e tubo de descarga para liberação de zoosporos; 14) esporo de resistência ornamentado; 15-16) Diplophlyctis sarcoptoides: 15) zoosporângio ornamentado com apófise, 16) zoosporângio de resistência ornamentado com apófise. 
Crusius \& Milanez 1989; Pires-Zottarelli 1990; Schoenlein-Crusius et al. 1990; SchoenleinCrusius et al. 1992; Pires-Zottarelli et al. 1996a; Schoenlein-Crusius \& Milanez 1998; PiresZottarelli 1999).

Comentários: os espécimes não apresentaram diferenças significativas com relação aos mencionados por Pires-Zottarelli (1990). Possuem zoosporângios e zoosporos maiores que os observados por Pires-Zottarelli et al. (1996a), que citam zoosporângios de 35-148 $\mu \mathrm{m}$. Diferem do observado por Pires-Zottarelli (1999), que cita zoosporângios menores, 30-150 $\mu$ m diâm. Foram isolados de celofane, palha de milho e epiderme de cebola, em amostras de água e solo.

Rhizophlyctis chitinophila Sparrow, Aquatic Phycomycetes 444-445. 1960.

Fig. 20

Talo eucárpico, monocêntrico, extramatrical.

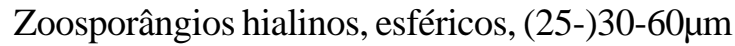
diâm., ovais, 40-50 x 35-45 um e irregulares, apresentando um tubo de descarga; parede lisa. Rizóides finos e delicados. Zoosporos encistados 7,5um diâm., com várias gotículas lipídicas. Esporos de resistência não observados.

Distribuição geográfica no Brasil: ocorre em SP(Lyra \& Milanez 1974; Pires-Zottarelli 1990). Comentários: as características dos espécimes isolados concordam com as descritas por Sparrow (1960) e diferem da descrição de Pires-Zottarelli (1990), que cita zoosporângios es-

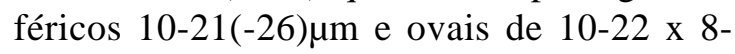
$14 \mu \mathrm{m}$. Foram isolados de exo-esqueleto de camarão, em amostras de solo.

\section{OOMYCOTA}

SAPROLEGNIALES

Leptolegniellaceae

Leptolegniella keratinophila Huneycutt, J. Elisha Mitchell Sci. Soc. 68:109. 1952.

Fig. 21
Micélio extensivo, ramificado, intramatrical; hifas irregulares, ramificadas. Esporos de resistência esféricos, 10-12 $\mu \mathrm{m}$ diâm., alongados 7-

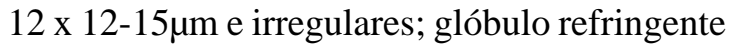
excêntrico.

Distribuição geográfica no Brasil: ocorre em SP (Pires-Zottarelli et al. 1996b e Pires-Zottarelli 1999).

Comentários: as características apresentadas pelos espécimes concordam com as descritas por Huneycutt (1952), Pires-Zottarelli et al. (1996b) e Pires-Zottarelli (1999). Foram isolados de ecdise de cobra, em amostras de solo.

\section{SAPROLEGNIACEAE}

Achlya dubia Coker, Saprolegniaceae, p. 135. 1923.

Fig. 22

Micélio extensivo em semente de sorgo; hifas ramificadas, 10-22 $\mu \mathrm{m}$ diâm. Gemas presentes. Zoosporângios clavados-longos, filiformes ou

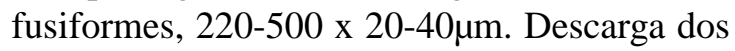
zoosporos traustotecóide, aclióide e dictióide; zoosporos encistados 10-12,5 $\mu \mathrm{m}$ diâm. Oogônios laterais, esféricos, 42-60 $\mu$ m; parede lisa, com poros nos pontos de atracação das células anteridiais. Anterídios díclinos, ocasionalmente ramificados; células anteridiais tubulares ou clavadas, atracação por projeções. Oosferas maturando. Oosporos 2-8 por oogônio, excêntricos, esféricos, 17-20 $\mu \mathrm{m}$ diâm. Germinação não observada.

Distribuição geográfica no Brasil: ocorre em MG (Beneke \& Rogers 1962); SP (SchoenleinCrusius \& Milanez 1989; Pires-Zottarelli 1990; Pires-Zottarelli et al. 1996b; Schoenlein-Crusius \& Milanez 1998).

Comentários: os espécimes apresentaram características que concordam com as descritas por Pires-Zottarelli (1990) e Pires-Zottarelli et al. (1996b). Apresentaram hifas com diâmetros menores e zoosporângios maiores que os descritos por Johnson (1956), que relatou hifas de 

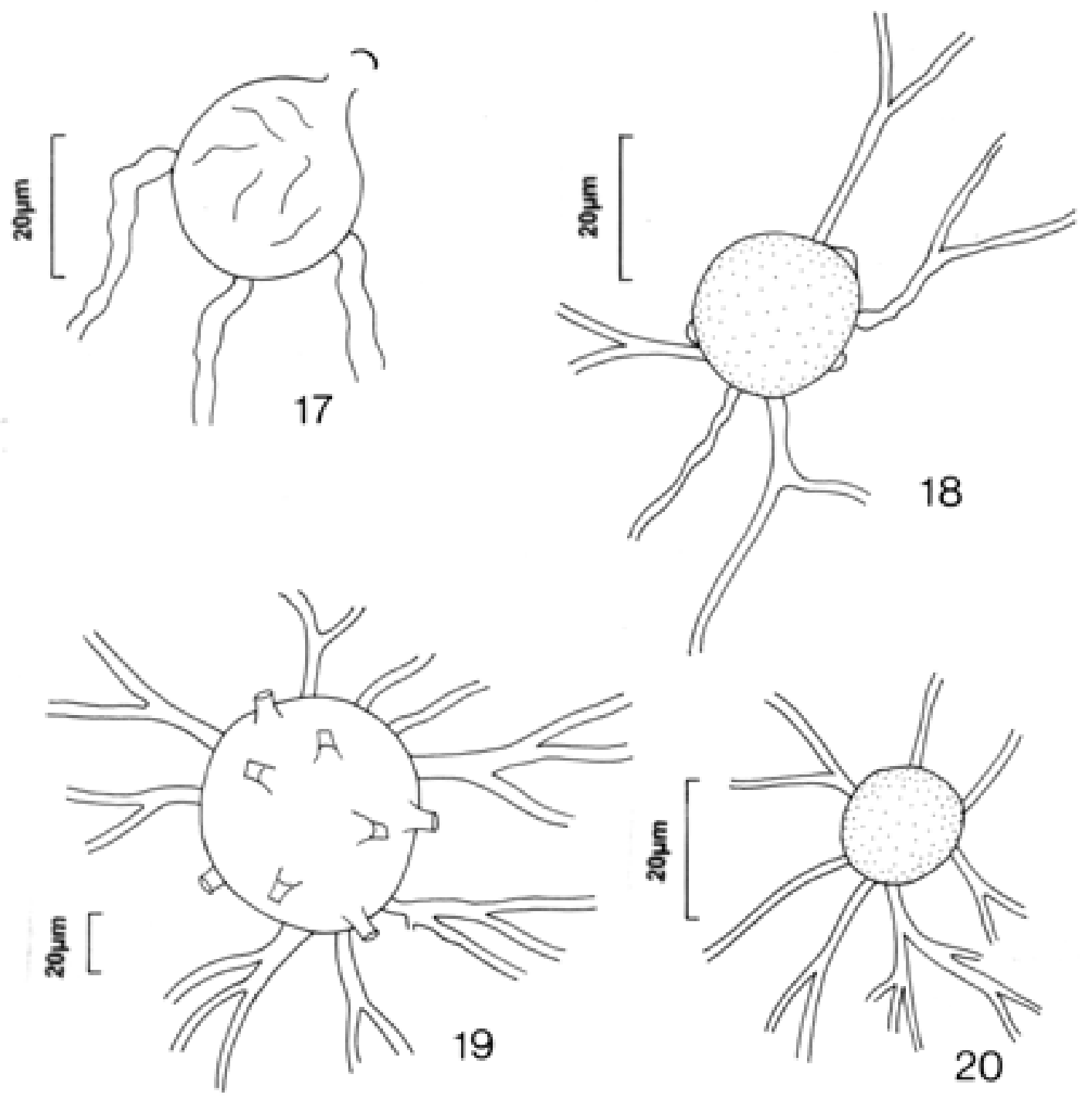

Figuras 17-20. 17-18) Karlingia granulata: 17) zoosporângio com 1 opérculo, 18) zoosporângio com 3 opérculos; 19) Karlingia rosea: zoosporângio endoperculado; 20) Rhizophlyctis chitinophila: zoosporângio inoperculado. 


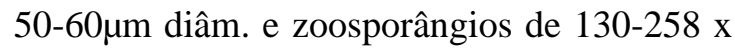
$8-15 \mu \mathrm{m}$. Foram isolados de semente de sorgo, em amostras de solo.

Achlya flagellata Coker, Saprolegniaceae, p.116. 1923.

Fig. 23

Micélio limitado em semente de sorgo; hifas ramificadas, 20-37 $\mu \mathrm{m}$ diâm. Gemas presentes. Zoosporângios fusiformes, 200-330 $\mu \mathrm{m}$ x 20-50 $\mu \mathrm{m}$; Descarga dos zoosporos aclióide;

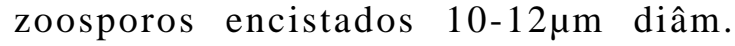
Oogônios laterais, esféricos, 45-70 $\mu$ m diâm., ocasionalmente piriformes; parede lisa, Anterídios presentes, díclinos, atracação por projeções. Oosferas freqüentemente não maturando. Oosporos 2-3 por oogônio, excên-

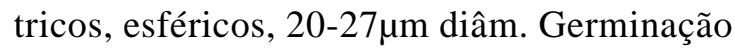
não observada.

Distribuição geográfica no Brasil: ocorre no AM (Karling 1944a-c); PB (Upadhyay 1967); RJ (Beneke \& Rogers 1970); SP (Milanez 1968; Milanez 1970; Rogers et al. 1970; Lyra \& Milanez 1974; Schoenlein-Crusius \& Milanez 1989; Pires-Zottarelli 1990; Schoenlein-Crusius et al. 1992; Schoenlein-Crusius \& Milanez 1998; Pires-Zottarelli 1999).

Comentários: as características apresentadas pelos espécimes concordam com as descritas por Johnson (1956), Pires-Zottarelli et al. (1996b) e Pires-Zottarelli (1999). Foram isolados de semente de sorgo, em amostras de solo.

Achlya orion Coker \& Couch, Saprolegniaceae, p. 112.1923.

Fig. 24

Micélio extensivo em semente de sorgo; hifas muito ramificadas, 17-30um diâm. Gemas presentes. Zoosporângios filiformes, 150-450 (-620)

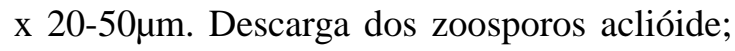
zoosporos encistados, 10-12,5 $\mu$ m diâm.

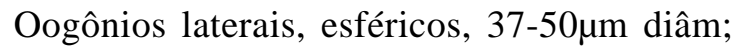
parede lisa; pedúnculos enrolados, torcidos ou curvos. Anterídios presentes; ramos anteridiais monóclinos; células anteridiais tubulares, atracação por projeções; tubo de fertilização ausente. Oosporos 2-4 por oogônio, excêntricos,

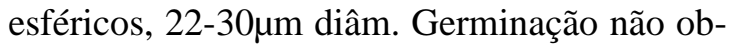
servada.

Distribuição geográfica no Brasil: ocorre em SP (Beneke \& Rogers 1962; Milanez 1970; Lyra \& Milanez 1974; Pires-Zottarelli 1990; PiresZottarelli et al. 1996b; Pires-Zottarelli 1999).

Comentários: os espécimes não apresentaram características diferentes do mencionado nas descrições de Johnson (1956), Pires-Zotarelli (1990), Pires-Zotarelli et al. (1996b) e PiresZottarelli (1999). Foram isolados de semente de sorgo, em amostras de solo.

Achlya oviparvula Rogers \& Beneke, Rickia 1:243-249. 1962.

Fig. 25

Micélio denso em semente de sorgo; hifas ramificadas, $17 \times 47 \mu \mathrm{m}$ diâm. Gemas presentes. Zoosporângios filiformes ou fusiformes, 160400 x 30-50 $\mu \mathrm{m}$. Descarga dos zoosporos aclióide; zoosporos encistados 10-12,5 $\mu$ m diâm. Oogônios esféricos, 22-27 $\mu \mathrm{m}$ diâm., alguns com projeções papiladas. Anterídios ausentes. Oosporos excêntricos, esféricos, 15-22 $\mu$ m diâm, 1-2 por oogônio, normalmente 1 .

Distribuição geográfica no Brasil: ocorre em SP (Rogers \& Beneke 1962; Pires-Zottarelli et al. 1996b; Pires-Zottarelli 1999) e RJ (Beneke \& Rogers 1970).

Comentários: os espécimes apresentaram características que concordam com as descritas por Rogers e Beneke (1962), Pires-Zottarelli et al. (1996b) e Pires-Zottarelli (1999). Foram isolados em semente de sorgo, em amostras de solo.

Achlya proliferoides Coker, Saprolegniaceae, p. 115. 1923.

Fig. 26

Micélio extensivo em semente de sorgo; hifas ramificadas 12-27 $\mu \mathrm{m}$ diâm. Gemas presentes.

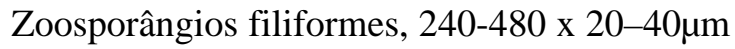




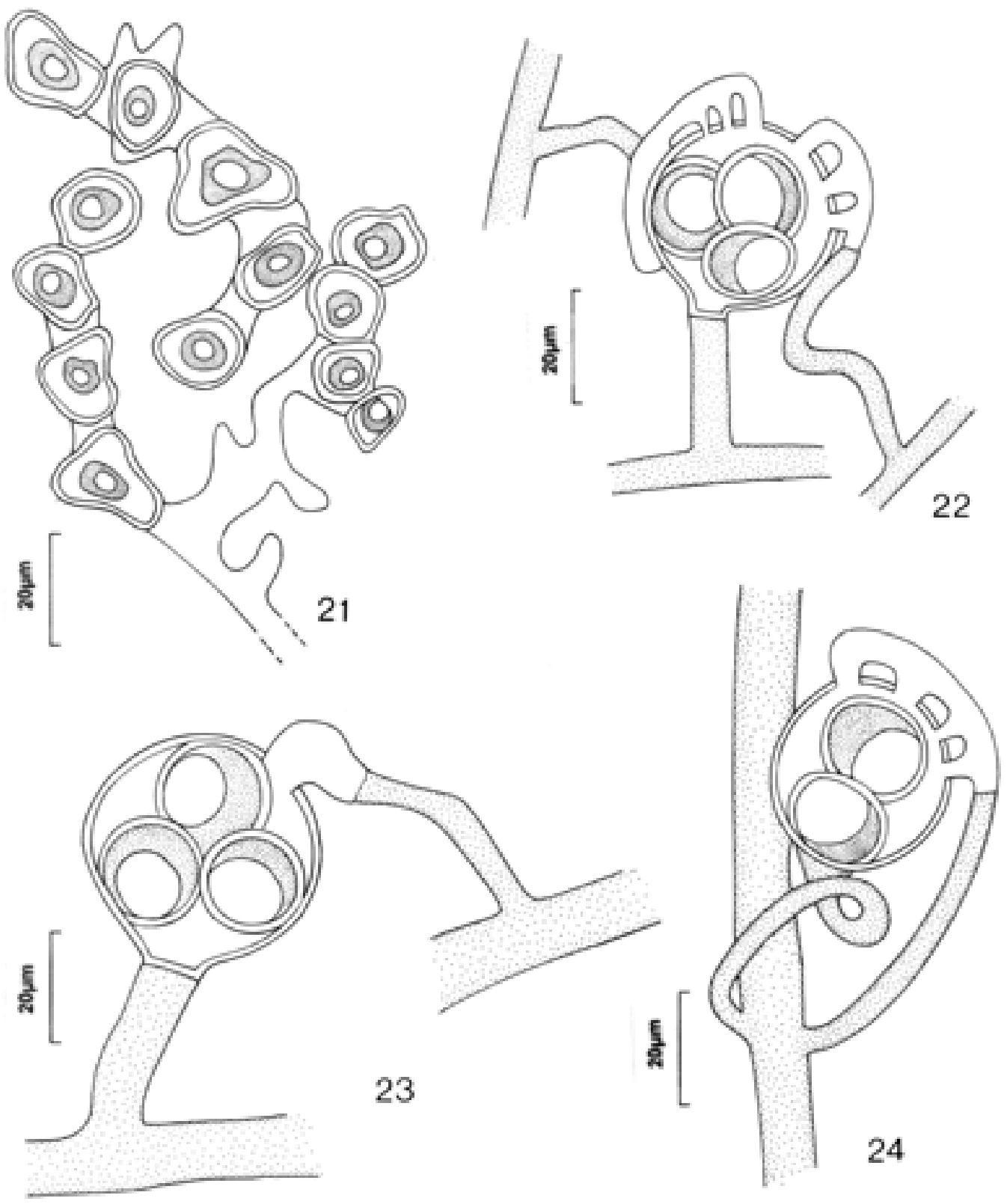

Figuras 21-24. 21) Leptolegniella keratinophila: esporos de resistência dentro das hifas; 22) Achlya dubia: oogônio lateral com oosporos excêntricos, anterídios díclinos; 23) Achlya flagellata: oogônio lateral, oosporos excêntricos, anterídio díclino; 24) Achlya orion: oogônio lateral, pedúnculo torcido, oosporos excêntricos, anterídio monóclino. 
diâm. Descarga dos zoosporos aclióide; zoosporos encistados 12,5 $\mu$ m diâm. Oogônios laterais, esféricos, 20-25 $\mu \mathrm{m}$ diâm. Anterídios díclinos e monóclinos enrolando nas hifas, pedúnculos e oogônios; células anteridiais irregulares ou tubulares; atracação lateral ou por projeções. Oosporos esféricos, 3-8 por oogônio, excêntricos, 17-22 $\mu \mathrm{m}$ diâm. Germinação não observada.

Distribuição geográfica no Brasil: MG (Beneke \& Rogers 1962; Rogers et al. 1970); PR (Beneke \& Rogers 1962) e SP (Rogers et al. 1970; Pires-Zottarelli et al. 1996b; PiresZottarelli 1999).

Comentários: os espécimes apresentaram oogônios esféricos menores que os descritos por

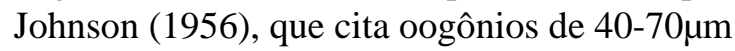
diâm.; dos descritos por Pires-Zottarelli et al. (1996b), de 40-69 um diâm. e daqueles mencionados por Pires-Zottarelli (1999), que cita oogônios de 29-46um diâm. Foram isolados em semente de sorgo, em amostras de água.

Aphanomyces euteiches Drechsler, J. Agri. Res. 30:311-312. 1925.

Fig. 27

Micélio delicado em ecdise de cobra e semente de sorgo, hifas ramificadas. Zoosporângios longos. Descarga dos zoosporos aclióide; zoosporos encistados $10 \mu \mathrm{m}$ diâm. Oogônios esféricos, laterais, 27-37 $\mu \mathrm{m}$ diâm; parede externa do oogônio lisa, e interna, irregular. Anterídios díclinos, 12 por oogônio; células anteridiais clavadas, atracação lateral; tubo de fertilização ausente. Oosporos 1 por oogônio, hialinos, esféricos, 22$27 \mu \mathrm{m}$ diâm., contendo uma gotícula lipídica; parede espessa. Germinação não observada.

Distribuição geográfica no Brasil: ocorre em SP (Pires-Zottarelli et al. 1996b, PiresZottarelli 1999).

Comentários: os espécimes se apresentam de acordo com as descrições de Scott (1961) e Pires-Zottarelli et al. (1996b). Difere do material descrito por Pires-Zottarelli (1999), que cita oogônios de 23-29um diâm. e oosporos de 16$21 \mu \mathrm{m}$ diâm. Foram isolados de semente de sorgo, em amostras de solo.

Aphanomyces irregulare Scott, A monograph of the Genus Aphanomyces, Va. Agr. Exp. Sta, Tech. Bul. 151:47-48. 1961.

Fig. 28

Micélio delicado em sementes de sorgo; hifas

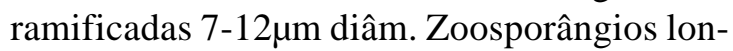
gos. Descarga dos zoosporos aclióide; zoosporos encistados $10 \mu \mathrm{m}$ diâm. Oogônios

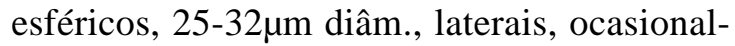
mente intercalares e terminais; parede oogonial irregular, papilas esparsas algumas vezes presentes, 2,5-6 4 m. Anterídios presentes; ramos anteridiais monóclinos; células anteridiais tubulares, simples, com atracação lateral; tubo de fertilização ausente. Oosporos excêntricos, 1 por oogônio, esféricos $15-20 \mu \mathrm{m}$ diâm. Germinação não observada.

Distribuição geográfica no Brasil: ocorre em SP (Pires-Zottarelli \& Milanez 1993).

Comentários: as características dos espécimes não diferem da descrição original de Scott (1961). Apresentaram oogônios maiores que os isolados por Pires-Zottarelli \& Milanez (1993), que citam oogônios de $18-22 \mu \mathrm{m}$ diâm. A presença de oogônios com paredes meramente irregulares e/ou com papilas esparsas e distribuídas irregularmente e a ausência de ornamentações espinhosas foram características marcantes para a colocação dos isolados em Aphanomyces irregulare. Howard et al. (1970) colocaram Aphanomyces irregulare como sinonímo de Aphanomyces scaber de Bary, tendo em vista que alguns isolados apresentaram paredes oogoniais meramente enrugadas e com ornamentações espinhosas, tuberculadas e papiladas. Johnson (1974) ressalta que Howard et al. (1970) fizeram precipitadamente a sinonimização e, que estas duas espécies devem ser melhor estudadas. Foram isolados de semente de sorgo, em amostras de solo. 

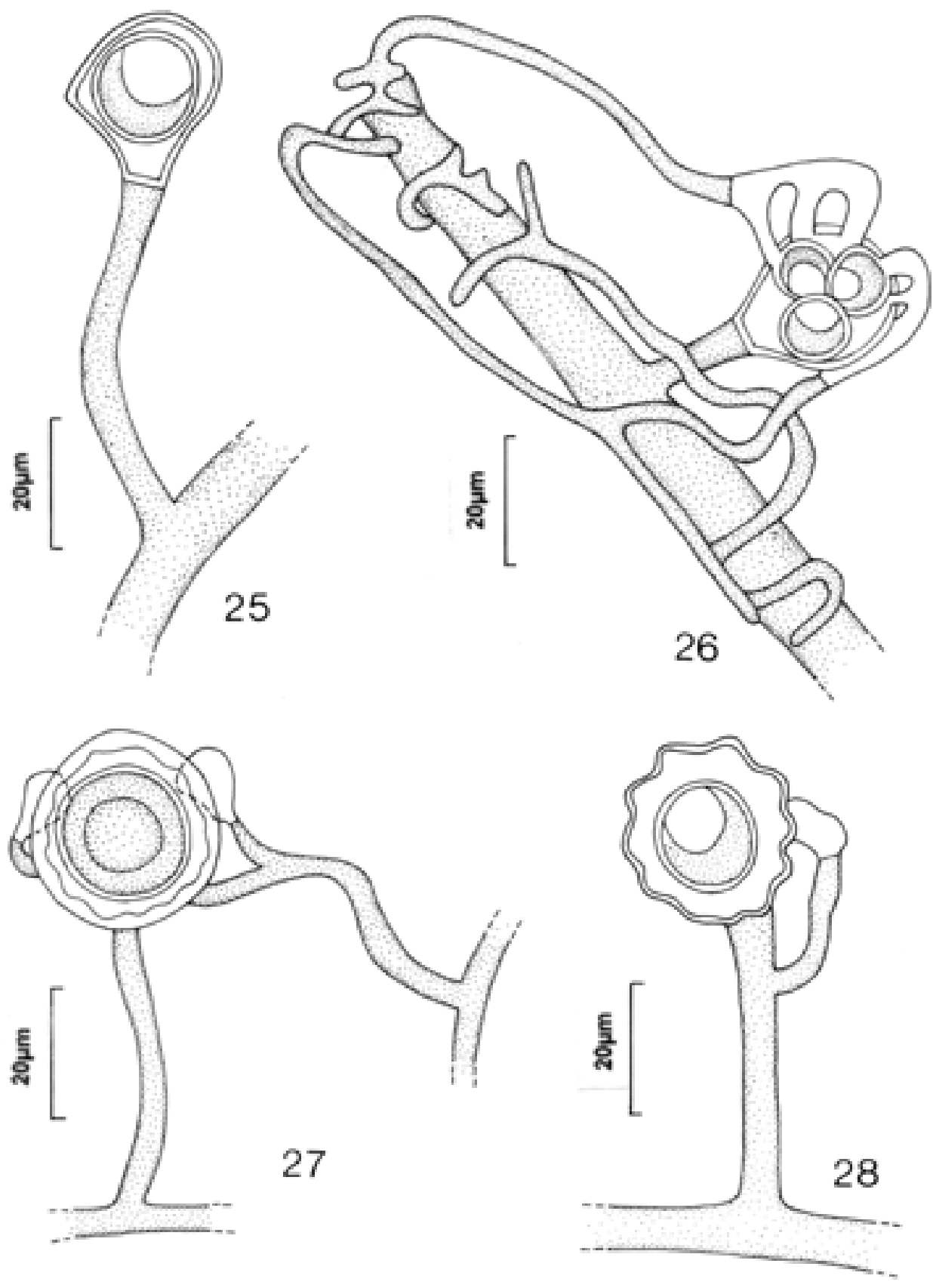

Figuras 25-28. 25) Achlya oviparvula: oogônio lateral com papila, oosporo excêntrico; 26) Achlya proliferoides: oogônio lateral com oosporos excêntricos e anterídios díclinos; 27) Aphanomyces euteiches: oogônio lateral com parede externa lisa e interna irregular, anterídio díclino; 28) Aphanomyces irregulare: oogônio lateral, oosporo excêntrico, parede irregular devido a presença de papilas, anterídio andrógino. 


\section{Brevilegnia $\mathrm{sp}_{1}$}

Micélio denso em sementes de sorgo e ecdise de cobra; hifas ramificadas. Zoosporângios com esporos em uma única fileira. Zoosporos ovais a esféricos; descarga dos zoosporos brevilegnióide. Oogônios laterais, esféricos 22$30 \mu \mathrm{m}$ diâm. Anterídios monóclinos e díclinos ramificados, 1-2 por oogônio, atracação lateral; célula anteridial clavada. Oosporos 1 por oogônio, cêntrico ou subcêntrico, esféricos, 15$22 \mu \mathrm{m}$ diâm.

Comentários: o tipo de liberação dos zoosporos enquadra os espécimes no gênero Brevilegnia, entretanto a presença de oosporos cêntricos e subcêntricos os diferencia do grupo. Estudos estão sendo encaminhados para finalização da identificação. Foram isolados de semente de sorgo e ecdise de cobra, em amostras de solo.

Dictyuchus pseudodictyon Coker \& Braxton ex Couch, J. Elisha Mitchell Sci. Soc. 46:228-229. 1931.

Fig. 29

Micélio limitado em sementes de sorgo; hifas ramificadas, 10-17 $\mu \mathrm{m}$ diâm. Zoosporângios fusiformes, destacando-se da hifa, 115-250 x 10$12 \mu \mathrm{m}$; redes falsa e verdadeira presentes. Descarga dos zoosporos dictióide; zoosporos encistados

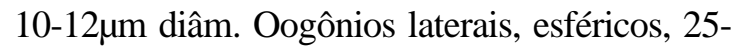
$35 \mu \mathrm{m}$ diâm; parede lisa. Anterídios monóclinos e díclinos, freqüentemente tortuosos e envolvendo os oogônios; células anteridiais tubulares, simples, atracação lateral ou por projeções. Oosporos 1 por oogônio, excêntricos, esféricos, 22-27um diâm. Germinação não observada.

Distribuição geográfica no Brasil: ocorre na PB (Upadhyay 1967) e SP (Beneke \& Rogers 1962; Pires-Zottarelli 1990; Pires-Zottarelli et al. 1996b; Pires-Zottarelli 1999).

Comentários: os espécimes apresentaram características que estão de acordo com as descritas por Pires-Zottarelli (1990) e Pires-Zottarelli et al. (1996b), diferindo das de Pires-Zottarelli

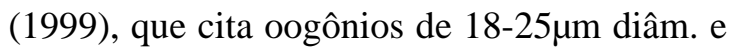
oosporos de 14-25um diâm. Foram isolados de semente de sorgo, em amostras de solo.

Saprolegnia ferax (Gruith.) Thuret, Ann. Sci. Nat. Bot., ser. III, 14:214. 1850.

Fig. 30

Micélio limitado em semente de sorgo; hifas 10$27 \mu \mathrm{m}$ diâm. Gemas presentes. Zoosporângios filiformes, $250-420$ x 20-40 $\mu$; renovação por proliferação interna. Descarga dos zoosporos saprolegnióide; zoosporos encistados 10-12,5 $\mu \mathrm{m}$ diâm. Oogônios laterais, intercalares e terminais,

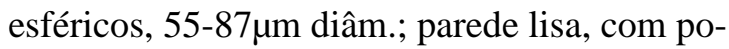
ros. Anterídios monóclinos. Oosporos 3-15 por

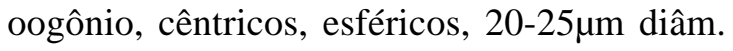
Germinação não observada.

Distribuição geográfica no Brasil: ocorre no AM (Karling 1946); MS (Karling 1946); MG (Beneke \& Rogers 1962); PE (Upadhyay 1967); RJ (Beneke \& Rogers 1970); SP (Milanez 1968; Rogers et al. 1970; Pires-Zottarelli 1990; PiresZottarelli et al. 1996b; Schoenlein-Crusius \& Milanez 1998; Pires-Zottarelli 1999).

Comentários: os espécimes apresentaram características que se enquadram na descrição de Seymour (1970), mas diferem da de PiresZottarelli (1990), que relatou zoosporângios menores, $81-280$ x 14-32 $\mu \mathrm{m}$, de Pires-Zottarelli et al. (1996b), que citam oosporos maiores, 26$37 \mu \mathrm{m}$ diâm., e de Pires-Zottarelli (1999), que cita zoosporângios menores, 40-200 x 16-27 $\mu \mathrm{m}$. Foram isolados de semente de sorgo, em amostras de água.

Saprolegnia parasitica Coker, Saprolegniaceae, p.57. 1923.

Fig. 31,32

Micélio limitado em semente de sorgo; hifas ramificadas, 10-25 $\mu \mathrm{m}$ diâm. Gemas presentes. Zoosporângios presentes, filiformes ou fusiformes, $250-400 \times 20-50 \mu \mathrm{m}$, renovação por proliferação interna. Descarga dos zoosporos saprolegnióide; zoosporos encistados 10-12 $\mu \mathrm{m}$ 
diâm. Oogônios terminais, intercalares, esféri-

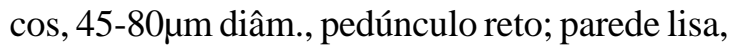
sem poros. Anterídios díclinos envolvendo os oogônios; células anteridiais tubulares ou clavadas, simples, atracação lateral; tubo de fertilização presente. Oosporos subcêntricos, 3-18

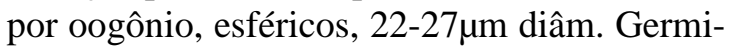
nação não observada.

Distribuição geográfica no Brasil: ocorre em MG (Beneke \& Rogers 1962); RJ (Beneke \& Rogers 1962); SP (Rogers et al. 1970; PiresZottarelli 1990; Schoenlein-Crusius et al. 1992; Pires-Zottarelli et al. 1996b; Schoenlein-Crusius \& Milanez 1998; Pires-Zottarelli 1999).

Comentários: as características apresentadas pelos espécimes estão de acordo com as descritas por Seymour (1970), Pires-Zottarelli (1990), Pires-Zottarelli et al. (1996b) e Pires-Zottarelli (1999). Foram isolados de semente de sorgo, em amostras de água.

Saprolegnia subterranea (Dissmann) Seymour, Nova Hedwigia, p.59-61. 1970.

Fig. 33,34

Micélio extensivo em semente de sorgo; hifas ramificadas., 12 x $22 \mu \mathrm{m}$ diâm. Gemas presentes. Zoosporângios fusiformes ou naviculados, 107-287 x 25-50 $\mu \mathrm{m}$; renovação por proliferação interna. Descarga dos zoosporos saprolegnióide; zoosporos encistados (7,5-)10$12,5 \mu \mathrm{m}$. Oogônios laterais, piriformes, 25-32 x 22-27 $\mu \mathrm{m}$ raramente esféricos; parede lisa, algumas vezes com poros nos pontos de atracação da célula anteridial. Anterídios andróginos; células anteridiais simples, atracação apical ou lateral; tubo de fertilização presente. Oosporos normalmente 1 por oogônio, cêntricos ou

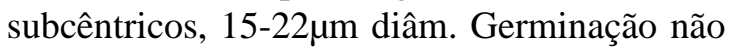
observada.

Distribuição geográfica no Brasil: ocorre em SP (Pires-Zottarelli et al. 1996b; Pires-Zottarelli 1999).

Comentários: os espécimes apresentaram oosporos menores que os mencionados por
Seymour (1970), que cita oosporos de 30-40(46) $\mu \mathrm{m}$. As características estão de acordo com as descrições de Pires-Zottarelli et al. (1996b) e Pires-Zottarelli (1999). Foram isolados de semente de sorgo, em amostras de solo.

\section{PERONOSPORALES}

Pythiaceae

Pythiogeton ramosum Minden, Falk. Mykolog. Untersuch. Berichte 2(2): 238. 1916.

Fig. 35

Colônias em CMA + p.p.e. com padrão de crescimento levemente roseta. Zoosporângios presentes, piriformes, 62-192 x 25-37 $\mu \mathrm{m}$, originando-se das hifas em ângulo de $90^{\circ}$. Ausência de reprodução sexuada.

\section{Distribuição geográfica no Brasil: RJ (Rogers} et al. 1970).

Comentários: A ausência de estruturas sexuais e o ângulo de inserção dos zoosporângios com relação às hifas caracterizam os isolados dentro dessa espécie, segundo Sparrow (1960) e Jee et al. (2000). Os espécimes apresentaram zoosporângios maiores que os citados por Sparrow (1932), o qual cita zoosporângios de até $60 \mu \mathrm{m}$ compr. e de Shen \& Siang (1948 apud Sparrow 1960), que citam zoosporângios de 28$65 \mu \mathrm{m}$ compr. por $24-53 \mu \mathrm{m}$ larg. Foram isolados de semente de sorgo, em amostras de água e solo. É a primeira citação para o estado de São Paulo.

Pythium irregulare Buisman, Diss. Univ. Utrecht., p. 38. 1927.

Fig. 36,37

Colônias em BCA (batata-cenoura-ágar) levemente roseta. Dilatações limoniformes presen-

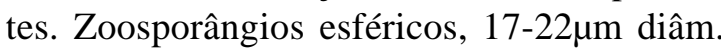
Oogônios intercalares, ocasionalmente laterais,

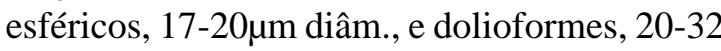
x 17-20 $\mu \mathrm{m}$; presença de papilas esparsas na parede dos oogônios. Anterídios monóclinos, 1-3 por oogônio; células anteridiais tubulares, sim- 

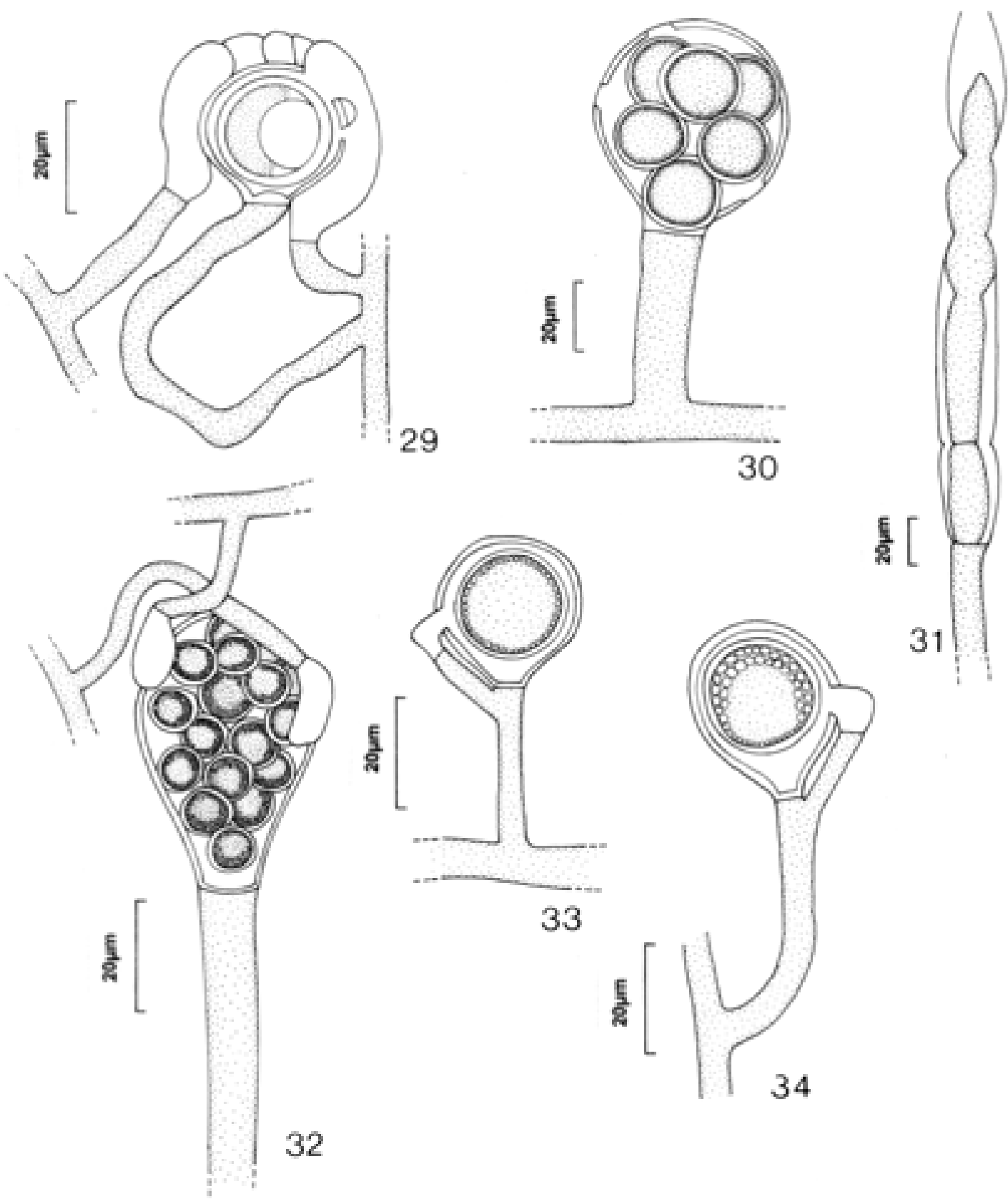

Figuras 29-34. 29) Dictyuchus pseudodictyon: oogônio lateral, oosporo excêntrico, anterídios díclino e monóclino; 30) Saprolegnia ferax: oogônio lateral esférico com poros na parede, oosporos cêntricos; 31-32) Saprolegnia parasitica: 31) zoosporângio com proliferação interna, 32) oogônio piriforme, terminal, oosporos subcêntricos, anterídios díclinos; 33 34) Saprolegnia subterranea: 33) oogônio piriforme, lateral, com oosporo cêntrico, anterídio andrógino, atracação apical, 34) oogônio piriforme, lateral, oosporo subcêntrico, anterídio andrógino. 
ples, atracação apical; tubo de fertilização presente. Oosporos apleróticos, 1(-2) por oogônio,

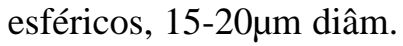

Distribuição geográfica no Brasil: ocorre em SP (Carvalho 1965).

Comentários: as características apresentadas pelos espécimes concordam com as descritas por Carvalho (1965) e Plaats-Niterink (1981). Foram isolados de semente de sorgo, em amostras de solo.

Pythium spinosum Sawada, Trans. Nat. Hist. Soc. Formosa 16: 199. 1926.

Fig. 38,39

Colônias em BCA com padrão de crescimento radiado. Dilatações hifálicas limoniformes terminais ou intercalares. Zoosporângios e zoosporos não formados. Oogônios ornamentados, laterais ou intercalares, $12-18 \mu \mathrm{m}$ diâm; ornamentações digitiformes ou espinosas. Anterídios monóclinos, 1 por oogônio; células anteridiais simples, atracação apical. Oosporos pleróticos, esféricos, 15-18 $\mu$ m diâm.

Distribuição geográfica no Brasil: ocorre em SP (Pires-Zottarelli et al. 1995; PiresZottarelli 1999).

Comentários: as características dos espécimes estão de acordo com a descrição de PlaatsNiterink (1981) e Pires Zottarelli (1999). Os isolados apresentaram oogônios menores que os citados por Pires-Zottarelli et al. (1995), que cita de 18-26um diâm. Foram isolados de semente de sorgo, em amostras de solo.

Pythium torulosum Coker \& Patterson, J. Elisha Mitchell Sci. Soc. 42:247. 1927.

Fig. 40

Colônias em BCA e CMA + p.p.e. sem padrão de crescimento. Hifas com dilatações hifálicas. Zoosporângios filamentosos inflados, formando complexos torulóides. Oogônios laterais, ocasionalmente intercalares, lisos, esféricos, 2230um diâm. Anterídios monóclinos ou díclinos; células anteridiais clavadas, simples, atracação apical. Oosporos pleróticos, raramente

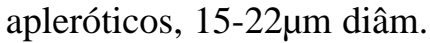

Distribuição geográfica no Brasil: ocorre em SP (Pires-Zottarelli \& Milanez 1993; PiresZottarelli et al. 1995; Pires-Zottarelli 1999).

Comentários: os espécimes apresentaram oogônios maiores quando comparados com a descrição da espécie dada por Plaats-Niterink

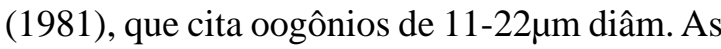
características concordam com a descrição apresentada por Pires-Zottarelli \& Milanez (1993), Pires-Zottarelli et al. (1995) e Pires-Zottarelli (1999). Foram isolados de semente de sorgo, em amostras de água e solo.

Pythium vexans de Bary, J. Bot. Paris 14: 105106. 1896.

Fig. 41

Colônias em BCA e CMA+ p.p.e. com padrão de crescimento roseta. Hifas com dilatações limoniformes. Zoosporângios esféricos, 12$17 \mu \mathrm{m}$ diâm. Oogônios laterais, ocasionalmente intercalares, esféricos, 22-27 $\mu \mathrm{m}$ diâm., lisos. Anterídios monóclinos; células anteridiais irregulares, clavadas, ou em forma de sino; atracação lateral. Oosporos apleróticos, ocasionalmente pleróticos, esféricos 17-22 $\mu$ m diâm.; parede

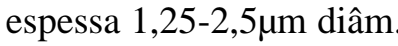

Distribuição geográfica no Brasil: ocorre em SP (Carvalho 1965; Pires-Zottarelli et al. 1995; Pires-Zottarelli 1999).

Comentários: as características dos espécimes concordam com a descrição de PlaatsNiterink (1981) e Pires-Zottarelli (1999), e diferem da de Pires-Zottarelli et al. (1995), que citam zoosporângios maiores, $17-36 \mu \mathrm{m}$

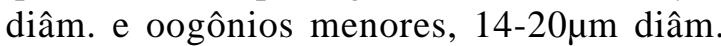
Foram isolados de semente de sorgo, em amostras de água.

Os resultados obtidos no presente estudo comprovam a natureza cosmopolita desse grupo de fungos e a existência dos mesmos em ambientes impactados. 


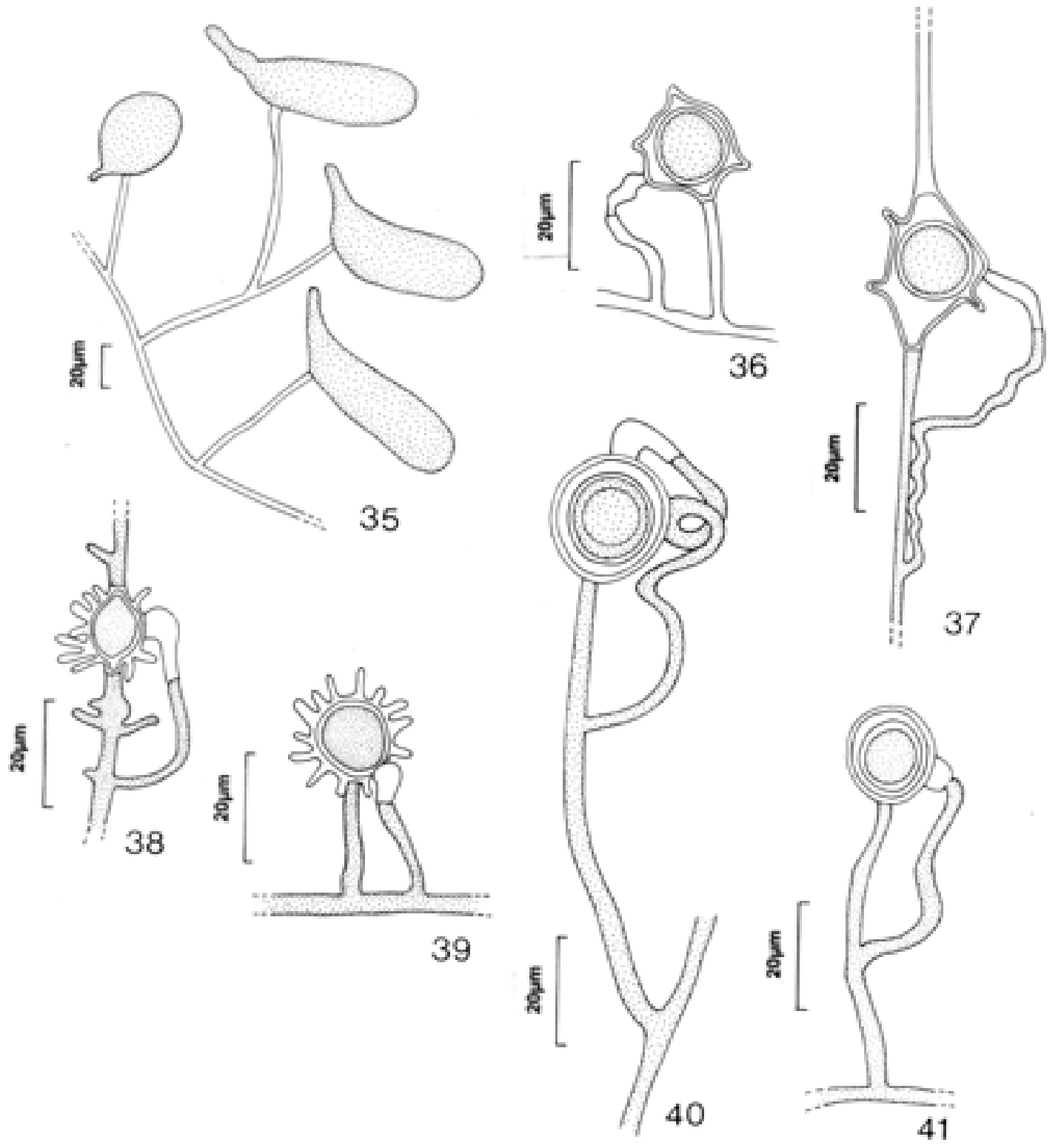

Figuras 35-41.35) Pythiogeton ramosum: zoosporângios saindo das hifas em ângulo de $90^{\circ} \mathrm{C}$; 36-37) Pythium irregulare: 36) oogônio lateral com papilas, anterídio monóclino, 37) oogônio intercalar; 38-39) Pythium spinosum: 38) oogônio intercalar ornamentado, anterídio monóclino, 39) oogônio lateral ornamentado, anterídio monóclino; 40) Pythium torulosum: oogônio lateral, anterídio andrógino; 41) Pythium vexans: oogônio lateral, anterídio andrógino. 


\section{Referências bibliográficas}

Alexopoulos, C. J.; Mims, C. W. \& Blackwell, M. B. 1996. Introductory Mycology. John Wiley, Sons, Inc., $4{ }^{\text {a }}$ ed. New York.

Apolinario, M. E. S. \& Milanez, A. I. 1986a. Leveduras e leveduróides de corpos d'água da região da Grande São Paulo. 3. Cryptococcus Kützing Emend. Phaff \& Spencer, Kloeckera Janke, Rhodotorula Harrison e Torulopsis Berlese. Rickia 13: 1-15.

Apolinario, M. E. S. \& Milanez, A. I. 1986b. Leveduras e leveduróides de corpos d'água da região da Grande São Paulo. 4. Trichosporun Behrend e Aureobasidium Viala \& Boyer. Rickia 13: 61-68.

Beneke, E.S.\& Rogers, L. 1962. Aquatic Phycomycetes isolated in the States of Minas Gerais, São Paulo and Paraná, Brazil. Rickia 1: 181-193.

Beneke, E.S.\& Rogers, L. 1970. Aquatic fungi of Parque Nacional de Itatiaia in the State of Rio de Janeiro. Rickia 5: 51-64.

Booth, T. 1979. Strategies for study of fungi in marine and marine influenced ecosystems. Revista de Microbiologia 10: 123-138.

Carvalho, P.C.T. 1965. Ocorrência no Brasil de algumas espécies de Pythium Pringsheimii de interesse a olericultura. Rickia 2: 89-106.

CETESB (Companhia de Tecnologia e Saneamento Ambiental). 1994. Sistema integrado de fiscalização e controle ambiental dos mananciais. CETESB. Secretaria do Meio Ambiente. São Paulo.

CETESB (Companhia de Tecnologia e Saneamento Ambiental). 1998. Seminário indicadores biológicos no controle de poluentes na represa do Guarapiranga, São Paulo. CETESB. Secretaria do Meio Ambiente. São Paulo.

Dick, M. 1973. Saprolegniales. Pp. 113-144. In: Ainsworth, G.C., Sparrow, F.K. , Sussman, A.S. (Eds.). The Fungi: an advanced treatise. Academic Press Inc, New York.v. 4B, cap.7.

Dick, M. 1976. The ecology of aquatic Phycomycetes. Pp. 513-542. In: Gareth Jones, E.B. (Ed.). RecentAdvances in Aquatic Mycology. London: Elek Science.

Dogma Jr., I. J. 1974a. Studies on chitinophylic Siphonaria, Diplophlyctis and Rizoclosmatium, Chytridiales. III. Nephochytrium complicatus Wiloughby: another Diplophlyctis with a sexual phase. Nova Hedwigia 25: 143-159.

Dogma Jr., I. J. 1974b. Studies on chitinophylic Siphonaria, Diplophlyctis and Rizoclosmatium, Chytridiales. II. Asterophlyctis sarcoptoides H. E.
Petersen: a Diplophlyctis with a sexual phase. Nova Hedwigia 25: 121-141.

Domingues, M. M. 1998. Levantamento da micota terrestre e determinação de alguns parâmetros abióticos do solo da região da Represa do Guarapiranga, no Município de São Paulo, SP. Monografia de conclusão de curso de graduação. Universidade Santo Amaro (São Paulo).

Gomes, S. P. 1997. Fungos micorrízicos arbusculares da Ilha dos Eucaliptos, Represa do Guarapiranga, São Paulo, SP. Monografia de conclusão de curso. Universidade Santo Amaro (São Paulo).

Howard, K. L.; Seymour, R. \& Johnson Jr., T. W. 1970. Aquatic fungi of Iceland: Saprolegniaceae. Journal of the Elisha Mitchell Scientific Society 86(2): 63-79.

Huneycutt, M.B. 1952. A new water mold on keratinized materials. Journal of the Elisha Mitchell Scientific Society 68: 109-112.

Jee, H. J.; Ho, H. H. \& Cho, W. D. 2000. Pythiogeton zeae sp. nov. causing root and stalk rot of corn in Korea. Mycologia 92(3): 522-527.

Joffily, I.M. 1947. Alguns ficomicetos aquáticos e terrícolas do Brasil. Boletim da Sociedade Brasileira de Agronomia 10(2): 95-113.

Johnson Jr., T.W. 1956. The genus Achlya: morphology and taxonomy. University of Michigan Press. Ann Arbor.

Johnson Jr., T.W. 1974. Aquatic fungi of Iceland: biflagellate species. Acta Naturalia Islandica 23: 1-40.

Karling, J. S. 1941. Cylindrochytridium johnstonii gen. nov. et sp. nov., and Nowakowskiella profusum sp. nov. Bulletin of the Torrey Botanical Club 68(6): 381-387.

Karling, J. S. 1944a. Brazilian anisochytrids. American Journal of Botany 31: 391-397.

Karling, J. S. 1944b. Brazilian chytrids. III. Nephrochytrium amazonensis. Mycologia 36: 350-367.

Karling, J. S. 1944c. Brazilian chytrids. IV. Species of Rozella. Mycologia 36(6): 638-647.

Karling, J. S. 1945a. Brazilian chytrids. VI. Rhopalophlyctis and Chytriomyces, two new chitinophylic operculate genera. American Journal of Botany 32(7): 362-369.

Karling, J. S. 1945b. Brazilian chytrids. V. Nowakowskiella macrospora n.sp., and other polycentric species. American Journal of Botany 32: 29-35.

Karling, J. S. 1946. Brazilian chytrids. IX. Species of Rhizophydium. American Journal of Botany 33: $328-334$. 
Karling, J. S. 1947. Brazilian chytrids.X. New species with sunken opercula. Mycologia 39: 56-70.

Karling, J. S. 1951. Cladochytrium setigerum sp. nov. and Septochytrium marilandicum sp. nov. from Maryland. Bulletin of the Torrey Botanical Club 78(1): 38-43.

Karling, J. S. 1964. Indian chytrids IV. Nowakowskiella multispora sp. nov. and other polycentric species. Sydowia Annales Mycologici, Ser. II. 17(1/6): 314-319.

Karling, J. S. 1965. Catenophlyctis, a new genus of the Catenariaceae. American Journal of Botany 52(2): 133-138.

Karling, J.S. 1977. Chytridiomycetarum Iconographia. J. Cramer. Vaduz.

Lyra, N.P. \& Milanez, A.I. 1974. Notas para o levantamento dos ficomicetos aquáticos do estado de São Paulo. Instituto de Micologia da Universidade Federal de Pernambuco. Publicação 698: 1-27.

Malosso, E. 1999. Hyphomycetes em ambientes aquáticos lôtico e lêntico - ocorrência e biomassa. Dissertação de Mestrado. Universidade Federal de São Carlos, São Paulo.

Milanez, A. I. 1968. Aquatic fungi of the "cerrado" region of São Paulo State. I. First Results. Rickia 3: 97-109.

Milanez, A. I. 1970. Contributions to the knowledge of aquatic Phycomycetes of São Paulo State. I. Oomycetes from the west region. Rickia 5: 23-43.

Milanez, A. I. 1984a. Fungos zoospóricos do estado de São Paulo. II. Chytridiomycetes da Região Oeste. Rickia 11: 115-127.

Milanez, A. I. 1984b. Distribuição geográfica de Karlingia rosea (de Bary \& Woronin) Johanson no Brasil. Pp. 73-76. In: Anais do Congresso da Sociedade Botânica de São Paulo, IV. Rio de Janeiro, 1984. SBSP.

Milanez, A. I. 1989. Fungos de águas continentais. Pp. 17-20. In: Fidalgo, O \& Bononi, V. L. (Coord.). Técnicas de coleta preservação e herborização de material botânico. Série Documentos. Instituto de Botânica, São Paulo.

Pires-Zottarelli, C. L. A. 1990. Levantamento dos fungos zoospóricos da Represa do Lobo ("Broa"), São Carlos-SP. Dissertação de Mestrado. Universidade Estadual Paulista, Rio Claro (São Paulo).

Pires-Zottarelli, C. L. A. 1999. Fungos Zoospóricos dos Vales dos Rios Moji e Pilões, Região de Cubatão, São Paulo SP. Tese de Doutorado. Universidade Estadual Paulista, Rio Claro (São Paulo).

Pires-Zottarelli, C. L. A. \& Milanez, A.I. 1993. Fungos zoospóricos da Represa do Lobo ("Broa"). Novas citações para o Brasil. Revista Brasileira de Botânica 16(2): 205-220.

Pires-Zottarelli, C.L.A.; Milanez, A. I.; SchoenleinCrusius, I. H.; Lohmann, L. G. 1995. Criptógamos do Parque Estadual das Fontes do Ipiranga, São Paulo, SP. Fungos, 3: Peronosporales. Hoehnea 22(1/2): 125-133.

Pires-Zottarelli, C. L. A.; Milanez, A. I.; SchoenleinCrusius, I. H.; Lohmann, L. G. 1996a. Criptógamos do Parque Estadual das Fontes do Ipiranga, São Paulo, SP. Fungos, 6: Chytridiales. Hoehnea 23(1): 77-90.

Pires-Zottarelli, C. L. A.; Milanez, A. I.; SchoenleinCrusius, I. H.; Lohmann, L. G. 1996b. Criptógamos do Parque Estadual das Fontes do Ipiranga, São Paulo, SP. Fungos, 4: Saprolegniales. Hoehnea 23(1): 39-66.

Plaats-Niterink, A.J. van der. 1981. Monograph of genus Pythium. Studies in Mycology 21: 1-242.

Rogers, A.L. \& Beneke, E.S. 1962. Two new species of Achlya in Brazil. Rickia 1: 243-249.

Rogers, A.L.; Milanez, A.I. \& Beneke, E.S. 1970. Additional aquatic fungi from São Paulo State. Rickia 5: 93-110.

Santos, M. L.; Pires-Zottarelli, C. L. A.; Trufem, S. F. B. 1996. Oomycota da Ilha dos Eucaliptos, Represa do Guarapiranga, São Paulo, SP. Pp. 166. In II Congresso Brasileiro de Micologia- Livro de resumos.

Santos, V.B.; Wellbaum, C.; Schoenlein-Crusius, I. H. 1998. Fungos filamentosos do solo da Ilha dos Eucaliptos na represa do Guarapiranga, em São Paulo-SP. Acta Botânica Brasilica 12(1): 101-110.

Schoenlein-Crusius, I.H. \& Milanez, A.I. 1989. Sucessão fúngica em folhas de Ficus microcarpa L.f. submersas no lago frontal situado no Parque Estadual das Fontes do Ipiranga, São Paulo, SP. Revista de Microbiologia 20(1): 95-101.

Schoenlein-Crusius, I. H. \& Milanez, A. I. 1998. Fungos zoospóricos (Mastigomycotina) da mata atlântica da Reserva Biológica do Alto da Serra de Paranapiacaba, município de Santo André, SP. Revista Brasileira de Botânica 21(2): 177-181.

Schoenlein-Crusius, I.H., Pires-Zottarelli, C.L.A. \& Milanez, A.I. 1990. Sucessão fúngica em folhas de Quercus robur L. (carvalho) submersas em um lago situado no município de Itapecerica da Serra, SP. Revista de Microbiologia 21: 61-67.

Schoenlein-Crusius, I.H., Pires-Zottarelli, C.L.A. \& Milanez, A.I. 1992. Aquatic fungi in leaves submerged in a stream in the Atlantic rainforest. 
Revista de Microbiologia 23: 167-171.

Scott, W.W. 1961. A revision of the genus Aphanomyces. Technical Bulletin Virginia Agricultural Experiment Station 151: 1-95.

Seymour, R.L. 1970. The genus Saprolegnia. Nova Hedwigia 19(1/2): 1-124.

Sparrow Jr, F. K. 1932. Observations on the aquatic fungi of Cold Spring Harbor. Mycologia 24(3): 268-302.

Sparrow Jr, F. K. 1952. A contribution to our knowledge of the Phycomycetes of Cuba. Revista de La Sociedad Cubana de Botanica 9: 68-74.

Sparrow Jr., F.K. 1957. A further contribution to the Phycomycete flora of Great Britain. Transactions of British Mycological Society 40: 523-535.

Sparrow Jr., F.K. 1960. Aquatic Phycomycetes. University of Michigan Press. $2^{\mathrm{a}}$ ed. Ann Arbor.

Upadhyay, H.P. 1967. Soil fungi from north-east Brazil. III. Phycomycetes. Mycopathologia et Mycologia Applicata 31(1): 49-62.

Wellbaum, C.; Schoenlein-Crusius, I. H. \& Santos, V. B. 1999. Fungos filamentosos em folhas do ambiente terrestre e aquático da Ilha dos Eucaliptos, Represa do Guarapiranga, São Paulo, SP. Revista Brasileira de Botânica 22(1): 69-74.

Willoughby, L.G. 1964. A study of the distribution of some lower fungi in soil. Nova Hedwigia 7(1/2): 133-150. 
Rocha, M. da. \& Zottareli, C. L. A. P. 